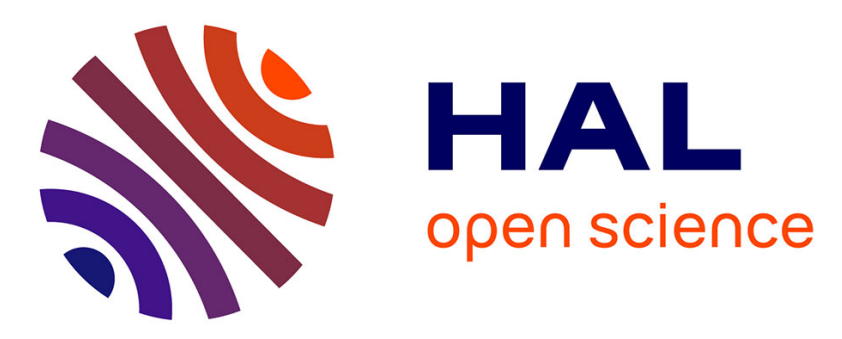

\title{
Clusters formation in ultralow-energy high-dose boron-implanted silicon
}

Fuccio Cristiano, Xavier Hebras, Nikolay Cherkashin, Alain Claverie, W. Lerch, S. Paul

\section{- To cite this version:}

Fuccio Cristiano, Xavier Hebras, Nikolay Cherkashin, Alain Claverie, W. Lerch, et al.. Clusters formation in ultralow-energy high-dose boron-implanted silicon. Applied Physics Letters, 2003, 83 (26), pp.5407-5409. 10.1063/1.1637440 . hal-01736115

\section{HAL Id: hal-01736115 https://hal.science/hal-01736115}

Submitted on 22 Mar 2018

HAL is a multi-disciplinary open access archive for the deposit and dissemination of scientific research documents, whether they are published or not. The documents may come from teaching and research institutions in France or abroad, or from public or private research centers.
L'archive ouverte pluridisciplinaire HAL, est destinée au dépôt et à la diffusion de documents scientifiques de niveau recherche, publiés ou non, émanant des établissements d'enseignement et de recherche français ou étrangers, des laboratoires publics ou privés. 


\section{Clusters formation in ultralow-energy high-dose boron-implanted silicon}

F. Cristiano, X. Hebras, N. Cherkashin, A. Claverie, W. Lerch, and S. Paul

Citation: Appl. Phys. Lett. 83, 5407 (2003); doi: 10.1063/1.1637440

View online: https://doi.org/10.1063/1.1637440

View Table of Contents: http://aip.scitation.org/toc/apl/83/26

Published by the American Institute of Physics

\section{Articles you may be interested in}

Transient enhanced diffusion of boron in $\mathrm{Si}$

Journal of Applied Physics 91, 8919 (2002); 10.1063/1.1471941

Rapid annealing and the anomalous diffusion of ion implanted boron into silicon

Applied Physics Letters 50, 416 (1987); 10.1063/1.98160

Trap-limited interstitial diffusion and enhanced boron clustering in silicon

Applied Physics Letters 66, 568 (1995); 10.1063/1.114015

$\{311\}$ defects in silicon: The source of the loops

Applied Physics Letters 73, 3748 (1998); 10.1063/1.122882

Diffusion of boron in silicon during post-implantation annealing

Journal of Applied Physics 69, 2135 (1991); 10.1063/1.348740

Transient boron diffusion in ion-implanted crystalline and amorphous silicon

Journal of Applied Physics 63, 1452 (1988); 10.1063/1.339926

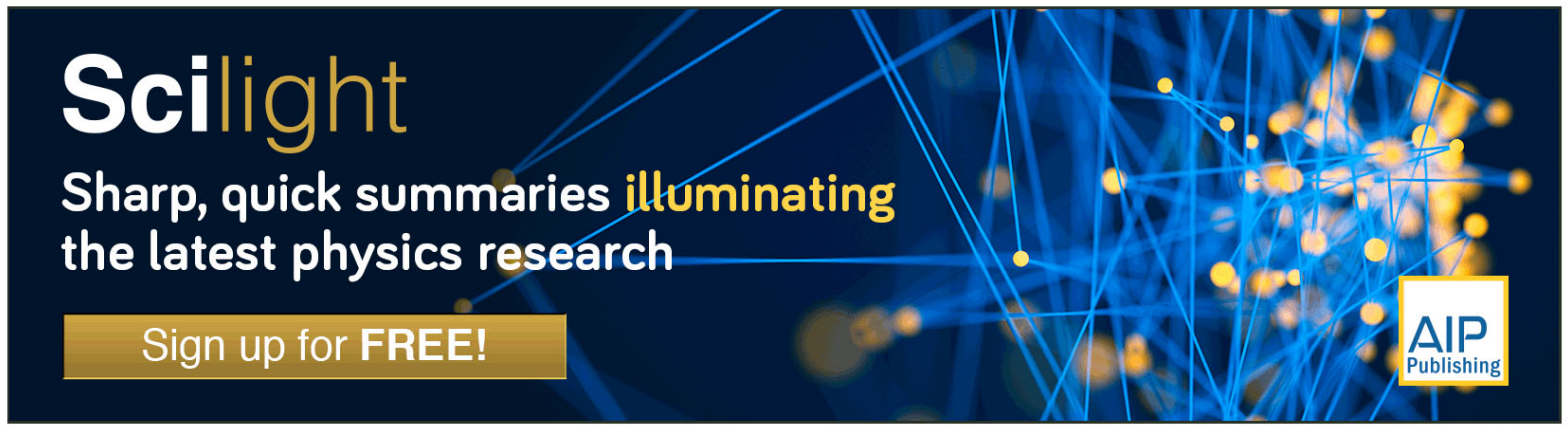




\title{
Clusters formation in ultralow-energy high-dose boron-implanted silicon
}

\author{
F. Cristiano, ${ }^{\text {a) }}$ X. Hebras, N. Cherkashin, and A. Claverie \\ Ion Implantation Group CEMES/LAAS-CNRS, 7 av. du Col. Roche, 31077 Toulouse, France
}

W. Lerch and S. Paul

Mattson Thermal Products GmbH, Daimlerstrasse 10, D-89160 Dornstadt, Germany

(Received 16 September 2003; accepted 7 November 2003)

\begin{abstract}
The formation and evolution of small cluster defects in $500 \mathrm{eV}, 1 \times 10^{15} \mathrm{~cm}^{-2}$ boron-implanted silicon is investigated. These clusters are identified by high-resolution transmission electron microscopy (TEM) as small dislocation loops lying on $\{100\}$ planes with an interstitial character. Weak-beam dark-field TEM analysis shows that, during annealing at $650{ }^{\circ} \mathrm{C}$, they evolve following an Ostwald ripening mechanism. Spike anneals at high temperatures make them dissolve but an immobile boron peak is still detected in the secondary ion mass spectroscopy profiles. Upon oxidation, the average size of the clusters increases, while boron electrical deactivation occurs. These results strongly indicate that the observed clusters contain both boron interstitials and silicon self-interstitials atoms. (C) 2003 American Institute of Physics. [DOI: 10.1063/1.1637440]
\end{abstract}

To continue scaling down complementary metal-oxidesemiconductor devices, ultrashallow and extremely highly doped $p^{+} / n$ junctions must be fabricated. ${ }^{1}$ As a consequence, boron is implanted at doses that exceed its equilibrium solid solubility limit in silicon. During annealing the boron peak region is therefore found to be immobile and electrical inactive. This is a major roadblock for meeting the ITRS specifications of low sheet resistance in the layers. Previous studies have invoked the formation of either a silicon boride phase $\left(\mathrm{SiB}_{4}{ }^{2,3} \text { or } \mathrm{SiB}_{3}\right)^{4}$ or $\mathrm{Si}-\mathrm{B}$ clusters (BICs) made of very few atoms ${ }^{5,6}$ to explain this behavior. However, while very few studies have investigated the formation of boron precipitates above the solid solubility limit, ${ }^{3,7,8}$ the formation of BICs has been mostly investigated at lower B concentrations. ${ }^{9,10}$ No transmission electron microscopy (TEM) evidence for BICs has been given so far, this being interpreted as BICs being very small objects involving only very few atoms. ${ }^{6}$ This description is supported by theoretical studies of the formation of BICs, which also assume that a very limited number of $\mathrm{Si}$ and $\mathrm{B}$ atoms are contained in the clusters. $^{5}$

In this letter, we present an experimental study of samples implanted in typical conditions for the formation of ultrashallow and extremely highly doped $p^{+} / n$ junctions. By using specific TEM imaging conditions it has been possible to establish the structure and to observe the evolution of small clusters formed during annealing in the implanted layers. These clusters definitely differ from already reported pure Si interstitial defects and probably result from the coprecipitation of $\mathrm{B}$ and $\mathrm{Si}$. We will show that, despite the very high B concentration levels $\left(\sim 10^{21} \mathrm{~cm}^{-3}\right)$, no precipitation of a boride phase is achieved in these structures and that, despite being much larger than "conventional" BICs, the observed clusters exhibit an annealing behavior typical of small boron-interstitial clusters.

Chemically etched (100) Si wafers of 8-20 $\Omega \mathrm{cm}$ were

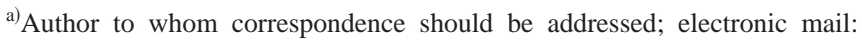
fuccio@laas.fr
}

implanted with $500 \mathrm{eV}$ boron ions to a dose of 1 $\times 10^{15}$ ions $/ \mathrm{cm}^{2}$ using a Varian VIIta-80 ULE high current implanter and annealed on a Mattson 2900 or 3000 rapid thermal annealing (RTA) system at 650 and $750{ }^{\circ} \mathrm{C}$ for times ranging from 2 to $160 \mathrm{~s}$ in flowing $\mathrm{N}_{2}$ or $\mathrm{O}_{2}$. Subsequent to a $650{ }^{\circ} \mathrm{C} 10 \mathrm{~s} \mathrm{~N}_{2}$ anneal (pre stabilization step), selected samples were spike annealed at 1050 and $1100{ }^{\circ} \mathrm{C}$ using a $250{ }^{\circ} \mathrm{C} / \mathrm{s}$ ramp-up rate. Boron concentration profiles have been measured by secondary ion mass spectroscopy (SIMS), while electrical activation has been assessed by sheet resistance and spreading resistance profiling (SRP) measurements. TEM analysis was performed on a JEOL 2010-HC system using weak-beam dark-field (WBDF) imaging conditions using a (220) diffracting vector, g. Selected samples were observed in high-resolution electron microscopy (HREM) conditions using a Philips CM30 microscope.

Figure 1 shows typical SIMS profiles obtained before and after annealing at several temperatures in a $\mathrm{N}_{2}$ ambient. Although not evident from the as-implanted curve, all SIMS profiles taken after annealing show that the boron concentration peak is located at a depth of about $2 \mathrm{~nm}$, in agreement with the expected value for an implantation energy of 500 $\mathrm{eV}$, while the boron peak concentration level clearly exceeds its solubility limit in silicon at all temperatures considered in



FIG. 1. $\mathrm{B}^{+}$SIMS profiles after implantation at $500 \mathrm{eV}$ to a dose of 1 $\times 10^{15} \mathrm{~cm}^{-2}$. Circles: as-implanted. Solid line: annealed at $650{ }^{\circ} \mathrm{C}$ for $10 \mathrm{~s}$. Dashed line: annealed at $650{ }^{\circ} \mathrm{C}$ for $10 \mathrm{~s}+$ spike anneal at $1050{ }^{\circ} \mathrm{C}$. Dotted line: annealed at $650{ }^{\circ} \mathrm{C}$ for $10 \mathrm{~s}+$ spike anneal at $1100{ }^{\circ} \mathrm{C}$. 




FIG. 2. (a) Typical weak-beam plan-view TEM image of a sample annealed at $650{ }^{\circ} \mathrm{C}$. (b) HREM cross-sectional image showing defects position at 2.5 $\mathrm{nm}$ below the surface.

this study (about $1.5 \times 10^{19}, 1.5 \times 10^{20}$, and $2 \times 10^{20} \mathrm{~cm}^{-3}$ at 650,1050 , and $1100^{\circ} \mathrm{C}$, respectively). ${ }^{7}$ Boron is therefore expected to easily precipitate. Unfortunately, after a low thermal budget anneal $\left(650^{\circ} \mathrm{C} 10 \mathrm{~s}\right.$, solid line in Fig. 1), it is not possible from the SIMS data to distinguish any immobile part of the profile (in the peak region) from the mobile one (diffusive tail). However, SRP measurements from samples annealed at $650{ }^{\circ} \mathrm{C}$ (not shown) indicate that, independently of the annealing time, the maximum boron activation level never exceeds $2 \times 10^{19} \mathrm{~cm}^{-3}$, suggesting that boron clustering actually occurs at this temperature. SRP measurements taken after spike anneals at 1050 and $1100^{\circ} \mathrm{C}$ show an increase in the electrical activation level, with sheet resistance values decreasing from $12000 \Omega / \square$ at $650^{\circ} \mathrm{C}$ down to 390 and $260 \Omega / \square$ at 1050 and $1100^{\circ} \mathrm{C}$, respectively. Nevertheless, it is found again that the maximum dopant activation does not exceed the solid solubility concentration level. This is confirmed by the SIMS profiles (dashed and dotted lines in Fig. 1, respectively), both exhibiting an immobile peak at high concentration levels (above $\sim 2 \times 10^{20} \mathrm{~cm}^{-3}$ ) and a diffusive tail at lower concentrations. It is important to note that, although boron clustering is detected at all annealing temperatures, the maximum concentration level of the immobile peak decreases from $2 \times 10^{21} \mathrm{~cm}^{-3}$ at $650^{\circ} \mathrm{C}$ to 5 $\times 10^{20} \mathrm{~cm}^{-3}$ at $1100^{\circ} \mathrm{C}$, indicating that the clusters formed during annealing are unstable with respect to the annealing temperature and tend to dissolve.

Figure 2(a) shows a typical WBDF plan-view image (g, $5 \mathrm{~g}$ ) of a sample annealed at $650^{\circ} \mathrm{C}$. Under these imaging conditions, small clusters appear as white circular dots on a dark background (indicated by arrows in the figure), with diameters ranging from 1 to about $10 \mathrm{~nm}$. HREM analysis in cross-section samples [Fig. 2(b)] shows that the observed defects are located at a depth of about $2.5 \mathrm{~nm}$ below the surface, corresponding to the location of the peak of the boron concentration profile (see Fig. 1). These defects have been observed in all samples annealed at low temperature $\left(650\right.$ and $\left.750{ }^{\circ} \mathrm{C}\right)$ independently of the annealing time and atmosphere $\left(\mathrm{N}_{2}\right.$ or $\left.\mathrm{O}_{2}\right)$. In contrast, no defects were detected after high temperature spike anneals at 1050 and $1100^{\circ} \mathrm{C}$. Figure 3(a) is an enlarged image of one defect, while Fig. 3(b) is obtained after Fourier filtering of the experimental image. Such image treatment allows us to identify these defects as being small dislocation loops lying on $\{100\}$ planes

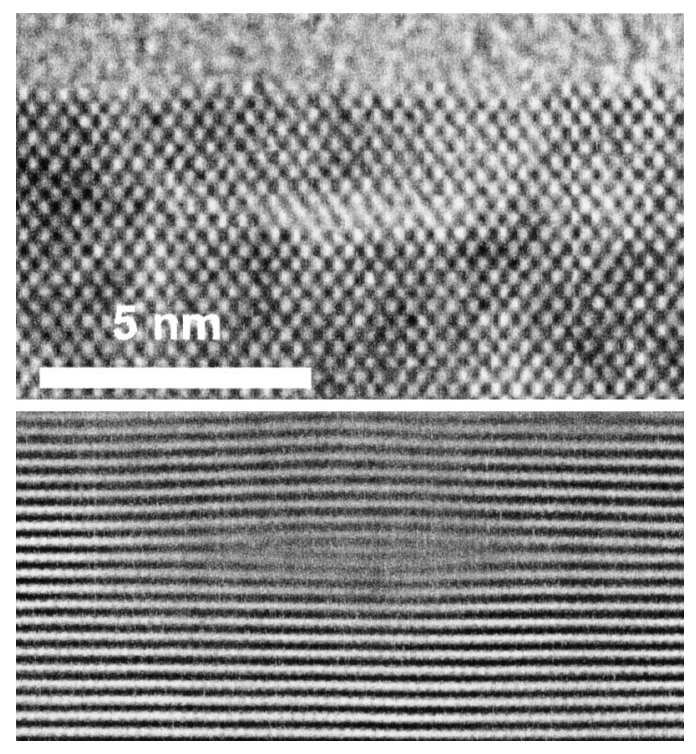

FIG. 3. (a) Original HREM image of a defect. (b) Fourier filtered image obtained using $\{200\}$ diffracted spots.

and exhibiting an interstitial character [see the extra plane in Fig. 3(b)]. This structure is consistent with the contrast observed under WBDF conditions on plan-view samples. Previous investigations of low-energy high dose boron implanted silicon did not report the presence of any kind of defects after annealing. ${ }^{11}$ There are two main reasons for that. The first one is that much higher temperature annealing is often used and the $\{100\}$ defects reported here probably dissolve during the ramp-up. The second reason is that these defects are not visible by TEM unless far-from-Bragg WBDF conditions are used, which is the only way to resolve the weak strain field surrounding these extremely small defects. On the other hand, the presence of "rod-like" defects lying on $\{100\}$ planes had already been reported in the 1970 s following higher energy $\mathrm{B}^{+}$implants $\left(40 \mathrm{keV}^{12}\right.$ and 100 $\mathrm{keV}){ }^{13}$ However, the habit plane of these defects was deduced on the basis of contrast extinction criteria without any evidence based on HREM. The difficulty in determining unambiguously the habit planes of these defects, due to their narrowness, suggests that the reported defects were instead the (today) well-known $\{113\}$ defects. ${ }^{14}$ The first HREM evidence of $\{100\}$ loops in $\mathrm{Si}$ was finally given a few years later in electron irradiated $\mathrm{Si}^{15}$ In order to investigate in more detail the nature of these clusters, we have studied by WBDF TEM their evolution upon annealing at $650{ }^{\circ} \mathrm{C}$. Figure 4 shows WBDF TEM micrographs [(a)-(c)] from samples annealed for 2, 10, and $160 \mathrm{~s}$, respectively. Despite the difficulty in extracting quantitative information from WBDF images of small clusters, due to the strong dependence of the clusters image size on the imaging conditions, ${ }^{16}$ these images clearly show that the average cluster size (of about $2 \mathrm{~nm}$ after $2 \mathrm{~s}$ annealing) increases by about a factor 3 after $160 \mathrm{~s}$, while their density decreases by one decade. This behavior is typical of an Ostwald ripening mechanism for the defect growth, ${ }^{17}$ where large clusters grow at the expense of the small ones by interchanging the atoms they are composed of. Additional experiments (not shown) suggest that the injection of $\mathrm{Si}$ atoms due to a slight oxidation of the surface results in the growth of these defects. The electrical activa- 

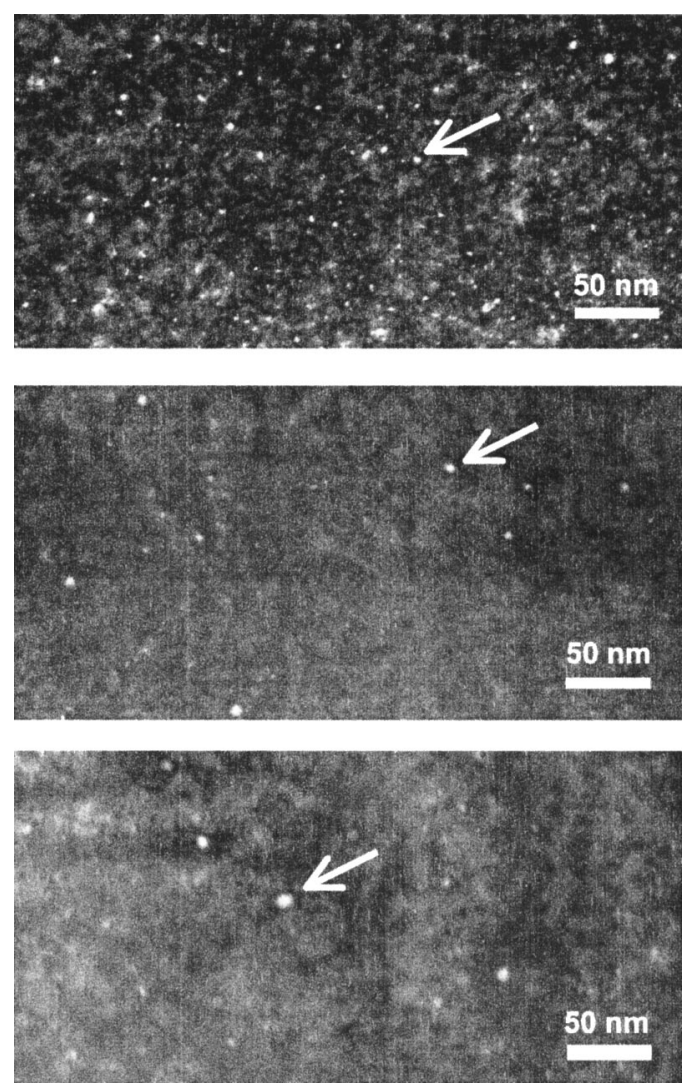

FIG. 4. TEM micrographs from samples annealed at $650^{\circ} \mathrm{C}$ for 2,10 , and $160 \mathrm{~s}$, respectively.

tion is also found to decrease during oxidation, in agreement with similar recent experiments. ${ }^{18}$

SIMS measurements (Fig. 1) have shown that boron exceeds its solubility limit for the experimental conditions used in this study and can therefore easily precipitate. Indeed, the fact that the defects are formed at the same depth as the peak of boron concentration, in conjunction with the observation of an immobile B peak even after high temperature annealing, clearly indicates that these defects must contain boron atoms. However, the maximum concentration level of the immobile peak progressively decreases when increasing the annealing temperature, indicating that the clusters tend to dissolve, i.e., they are not the precursors of a stable second phase, typical of a precipitation process above solid solubility. In such cases, precipitates are observed well above $1000{ }^{\circ} \mathrm{C} .{ }^{3,7,8}$ In addition, although they are still detected by SIMS at high temperature, they are no longer seen by TEM, indicating that their size probably decreases below the TEM detection limit. The observed growth of the $\{100\}$ loops during oxidation ( $\mathrm{Si}$ interstitials injection conditions) suggests that these defects probably contain Si atoms. However, they cannot be pure Si interstitials defects, as, although small, pure $\mathrm{Si}$ defects of the observed dimensions would contain hundreds of atoms and rearrange in more energetically favor- able forms $[\{113\} s$ or (111) dislocation loops], easily detectable by TEM. ${ }^{17}$ In addition, calculations of the strain field surrounding the defects ${ }^{19,20}$ show that, should the defects consist of Si atoms only, each of them would be able to trap less than one B atom at its periphery. The observed defect density (of the order of $10^{12} \mathrm{~cm}^{-2}$ ) cannot therefore account for the amount of immobile boron atoms estimated by SIMS (no less than $10^{14} \mathrm{~cm}^{-2}$ ), i.e., boron atoms must be contained in the core of the defects. The most probable explanation of the results obtained in this work is therefore that the $\{100\}$ defects are B-Si interstitial complexes, i.e., BICs of hundreds of atoms. This might be the evidence that BICs can be imaged by TEM and thus can be much bigger than generally assumed.

In summary, we have studied the structure and thermal evolution of small two-dimensional $\{100\}$ clusters found after RTA annealing of ultralow energy high-dose $\mathrm{B}^{+}$implanted Si. During annealing at low temperature, these defects evolve following an Ostwald ripening mechanism. Spike anneals at high temperatures make them dissolve but a secondary peak of boron remains in the profile. Both $\mathrm{Si}$ and $\mathrm{B}$ atoms are contained in the defects. These results indicate that boron interstitial clusters can be imaged by TEM and thus can be much bigger than generally assumed.

This work is part of the FRENDTECH Project and funded by the EC as IST/2000-30129.

${ }^{1}$ E. C. Jones and E. Ishida, Mater. Sci. Eng., R. 24, 1 (1998).

${ }^{2}$ S. Solmi, E. Landi, and F. Baruffaldi, J. Appl. Phys. 68, 3250 (1990).

${ }^{3}$ A. Agarwal, H. J. Gossman, D. J. Eaglesham, L. Pelaz, S. B. Herner, D. C. Jacobson, T. E. Haynes, and R. Simonton, Mater. Sci. Semicond. Process. 1, 17 (1998).

${ }^{4}$ N. E. B. Cowern, M. J. J. Theunissen, F. Roozeboom, and J. G. M. van Berkum, Appl. Phys. Lett. 75, 181 (1999).

${ }^{5}$ L. Pelaz, G. H. Gilmer, H.-J. Gossmann, C. S. Rafferty, M. Jaraiz, and J. Barbolla, Appl. Phys. Lett. 74, 3657 (1999).

${ }^{6}$ P. Pichler, Mater. Res. Soc. Symp. Proc. 717, 103 (2002).

${ }^{7}$ A. Armgliato, D. Nobili, P. Ostoja, M. Servidori, and S. Solmi, in Electrochem. Soc. Proc. 77-2: Semiconductor Silicon 1977, edited by H. R. Huff and E. Sirtl, (1977), p. 638.

${ }^{8}$ T. L. Aselage, J. Mater. Res. 13, 1786 (1998).

${ }^{9}$ N. E. B. Cowern, K. T. F. Janssen, and H. F. F. Jos, J. Appl. Phys. 68, 6191 (1990).

${ }^{10}$ S. Solmi, F. Baruffaldi, and R. Canteri, J. Appl. Phys. 69, 2135 (1991).

${ }^{11}$ L. H. Zhang, K. S. Jones, P. H. Chi, and D. S. Simons, Appl. Phys. Lett. 67, 2025 (1995).

${ }^{12}$ P. K. Madden and S. M. Davidson, Radiat. Eff. 14, 271 (1972).

${ }^{13}$ W. K. Wu and J. Washburn, Cryst. Lattice Defects 7, 39 (1977).

${ }^{14}$ J. A. Lambert and P. S. Dobson, Philos. Mag. 44, 1043 (1981).

${ }^{15}$ M. Pasemann, D. Hoehl, A. L. Aseev, and O. P. Pchelyakov, Phys. Status Solidi 80, 135 (1983).

${ }^{16}$ M. L. Jenkins, M. A. Kirk, and H. Fukushima, J. Electron Microsc. 48, 323 (1999).

${ }^{17}$ A. Claverie, B. Colombeau, B. De Mauduit, C. Bonafos, X. Hebras, G. B. Assayag, and F. Cristiano, Appl. Phys. A: Mater. Sci. Process. 76, 1025 (2003).

${ }^{18}$ L. Radic, A. D. Lilak, and M. E. Law, Appl. Phys. Lett. 81, 826 (2002).

${ }^{19}$ J. P. Hirth and J. Lothe, Theory of Dislocations, (McGraw-Hill, New York, 1968), pp. 462-465.

${ }^{20}$ J. F. Gibbons, Radiat. Eff. 6, 313 (1970). 